\title{
Effect of Moisture Content on Engineering Properties of Green Gram for Designing of Agricultural Equipment
}

Bhabani Shankar Dash, Sangram Keshari Swain, Debaraj Behera, Kalpana Rayaguru1, Megha Meshram

10.18805/ajdfr.DR-1683

\begin{abstract}
Background: Green gram is a popular pulse crop in India (with 2.02 MT production over a cultivated area of 4.26 Mha) and Odisha (20.8 lakh ha area with a yield of 10.60 lakh tonnes). The information on the engineering properties and its behavioural changes with moisture content is vital for handling and designing of different agricultural processing equipment.

Methods: This work mainly focused on studying green gram variety's (Sujata) engineering properties at five different moisture levels (within a moisture range of 10.58 to $45.45 \%$ (d.b.). Standard methods and procedures were followed in the study and the output results were compared with previous research work to justify the variation or anomaly in some cases. The curve estimation method (regression analysis) was followed to find the best-fit curve and equation for the parameters studied.

Result: The geometric mean diameter (GMD) of grain increased from 3.75 to $4.12 \mathrm{~mm}$ within the moisture content (MC) range and the variation was statistically significant $(p<0.05)$. Sphericity and surface area varied significantly from 0.83 to 0.82 and 44.13 to 53.45 $\mathrm{mm}^{2}$, respectively, within the range of moisture contents studied with a high correlation among the data. Mass of thousand grains augmented (44.13 to $53.45 \mathrm{~g}$ ) with a rise in $\mathrm{MC}$ and the data followed logarithmic and inverse curves. Bulk and true densities of green gram declined significantly from 860 to $670 \mathrm{~kg} \mathrm{~m}^{-3}$ and 1330 to $1240 \mathrm{~kg} \mathrm{~m}^{-3}$ with an increase in the moisture content. The porosity of green gram increased significantly from $35.75 \%$ to $46.38 \%$ and the terminal velocity raised from $9.20 \mathrm{~m} \mathrm{~s}^{-1}$ to $11.10 \mathrm{~m} \mathrm{~s}^{-1}$ with an increase in MC. The dynamic angle of repose increased significantly from 30.95 to $46.57^{\circ}$ with MC. A significant variation in the coefficient of internal friction ( 0.78 to 0.90$)$ was observed for the grains. The coefficient of static friction of grain increased significantly for different surfaces (MS, SS, Plywood and GI) with a rise in MC. The MS surface produced the highest coefficient of static friction and SS had the least. The results confirmed significant effect of MC on all engineering properties of green gram.
\end{abstract}

Key words: Angle of repose, Bulk density, Coefficient of friction, Green gram, Moisture content, Porosity.

\section{INTRODUCTION}

Pulses contribute significantly to our daily diet and have been a rich source of protein and carbohydrates for its consumers. Pulses grown in India include grams, pigeon pea, lentil, field peas, etc. The country's diverse climate and soil types have played a vital role in cultivating pulse crops in the subcontinent. The primary pulse growing states are Madhya Pradesh (20.3\%), Maharashtra (13.8\%), Rajasthan (16.4\%) and Uttar Pradesh (9.5\%) (Singh et al., 2015). The green gram production recorded was around 2.02 MT over a cultivated area of 4.26 Mha (Kharif + rabi) and at a yield level of $472 \mathrm{~kg} \mathrm{ha}^{-1}$. The major green gram producing states are Rajasthan, Madhya Pradesh, Maharashtra, Karnataka, Bihar, Andhra Pradesh, Odisha and Tamil Nadu (Anon., 2018). In Odisha, it is widely cultivated just after the Paddy crop and is very popular in our day-to-day diet. In Odisha, pulses are grown in 20.8 lakh ha with 10.60 lakh tonnes yield and green gram contributes $42 \%$ of total pulse area with a production of 4.14 lakh tonnes (OUAT Strategies, 2016). Being a legume, pulses require less fertiliser, the water requirement of the crop is low and it fits nicely in crop rotation with cereals. The primary chemical components of green gram include carbohydrates, proteins, fat, fibre, ash, fatty acids and amino acids, with protein contributing up to 14.6-33.0 g/100 g of seed (Dahiya et al., 2015).
Department of Farm Machinery and Power, College of Agricultural Engineering and Technology, Odisha University of Agriculture and Technology, Bhubaneswar-751 003, Odisha, India.

'Department of Agricultural Processing and Food Engineering, College of Agricultural Engineering and Technology, Odisha University of Agriculture and Technology, Bhubaneswar-751 003, Odisha, India.

Corresponding Author: Bhabani Shankar Dash, Department of Farm Machinery and Power, College of Agricultural Engineering and Technology, Odisha University of Agriculture and Technology, Bhubaneswar-751 003, Odisha, India.

Email: dash.bhabani2009@gmail.com

How to cite this article: Dash, B.S., Swain, S.K., Behera, D., Rayaguru, K. and Meshram, M. (2021). Effect of Moisture Content on Engineering Properties of Green Gram for Designing of Agricultural Equipment. Asian Journal of Dairy and Food Research. DOI: 10.18805/ajdfr.DR-1683.

Submitted: 15-04-2021 Accepted: 07-06-2021 Online: 03-08-2021

The knowledge of engineering properties of green gram is vital, considering its wide use and cultivation in the state. Information on size, shape, sphericity, bulk density, true density and porosity is essential for designing the equipment for handling, harvesting, sieving, sorting and grading, drying 
and storing the grain (Pandiselvam et al., 2015, Rani and Grewal, 2014, Sahay and Singh, 1994). The angle of repose and co-efficient of friction is essential in designing seed drill hoppers, bins, silos, storage structures, dehulling and packaging equipment (Niveditha et al., 2013, Singh et al., 2010). The bulk density of the grain plays a crucial role in determining the capacity of seed hoppers. Several researchers, including Mangaraj et al., 2005, Nimkar and Chattopadhaya, 2001, Pandiselvam et al., 2017, Sharon et al., 2015 and Unal et al., 2008 have studied on physical and engineering properties of a Green gram and few have considered their relation with moisture content. However, few researches have been reported on the varieties of green gram grown and found in Odisha. This paper investigates the engineering properties of a variety (Sujata) of green gram grown in Odisha. The properties like size (length, breadth, thickness), sphericity, grain weight, volume, bulk density, true density, porosity, static friction, coefficient of internal friction, angle of repose and terminal velocity are thoroughly studied over a wide range of moisture contents with $5,10,15$ and $20 \%$ increase in existing moisture content levels. Then, the existing relationship between these grain properties and MC's rise was analysed using suitable statistical methods.

\section{MATERIALS AND METHODS}

\section{Sample preparation}

The green gram variety was procured from International centre for Agricultural Research in Dry Area (ICARDA), Odisha and cleaned manually to separate foreign matter. It was passed through a sieve to separate broken and immature grains. The graded and clean grain was sundried and its initial moisture content was determined using a hot air oven method. The grain samples were then added with a calculated amount of distilled water at four increments $(5,10,15$ and $20 \%)$ and put in airtight polyethene pouches. The samples were kept in the refrigerator at $5^{\circ} \mathrm{C}$ for a week to ensure uniform moisture distribution throughout the sample (Nimkar and Chattopadhyay, 2001, Singh et al., 2010). Before conducting the tests, the sample of required quantities were taken out of the refrigerator and put at room temperature. The actual moisture content (MC) of the sample were measured by placing them in a hot air oven at $103 \pm 2^{\circ} \mathrm{C}$ for $72 \mathrm{~h}$ followed by cooling and weighing to determine its MC (Nimkar and Chattopadhyay, 2001). The final MC of different treatments of grain observed after placing them in room temperature were $10.58,20.25,26.88,36.23$ and $45.45 \%$ (d.b.). Measurement of several engineering properties (Physical, aerodynamic and mechanical properties) was done at different moisture content levels with three replications at Department of Agricultural Processing and Food Engineering laboratory, College of Agricultural Engineering and Technology, OUAT in the year 2020.

\section{Size}

For measuring the grain's dimensions, 50 grains were selected randomly from the sample and their three principal dimensions (length, width and thickness) were measured using a digital Vernier calliper with a least count of 0.01 $\mathrm{mm}$. The geometric mean diameter (GMD) $D_{\mathrm{m}}$ was computed using the following equation (Singh et al., 2010 and Pawase et al., 2019):

$$
D_{m}=(L B T)^{1 / 3}
$$

\section{Sphericity}

The degree of sphericity $\phi_{\mathrm{g}}$ is derived from the geometric dimensions and calculated using the following equation (Singh et al., 2010):

$$
\phi_{g}=(\mathrm{LBT})^{1 / 3} / \mathrm{L}
$$

\section{Surface area}

The surface area of green gram $\left(\mathrm{S}_{\mathrm{g}}\right)$ was determined as per the equation used by Dursun and Dursun, 2005 and Singh et al., 2010 with GMD as the grain's representative sphere.

$$
\mathrm{S}_{\mathrm{g}}=\pi \mathrm{D}_{\mathrm{m}}^{2}
$$

\section{Thousand-grain weight}

Determination of thousand-grain weight $\left(\mathrm{W}_{\mathrm{g}}\right)$ was done as per the standard IS 4333 part IV (ISI, 1968b) at different moisture contents.

\section{Bulk density}

The bulk density $\left(\rho_{\mathrm{bg}}\right)$ is the ratio of the mass of grain to its total volume. It was obtained by filling a measuring cylinder or container of known mass with a green gram. Then the contents are weighed using an electronic digital balance with an accuracy of $0.001 \mathrm{~g}$. Following equation (4) was used to calculate bulk density (Singh et al., 2010).

$$
\rho_{\mathrm{bg}}=\mathrm{M} / \mathrm{V}
$$

\section{True density}

The true density $\rho_{\operatorname{tg}}$ is the ratio between the grain mass and actual volume of grain, i.e., volume devoid of external pore spaces. It was determined using the toluene displacement method (Pandiselvam et al., 2017, Singh et al., 2010).

\section{Porosity}

The porosity of the grain (bulk) $(\varepsilon)$ is the ratio of the volume of the void to the total bulk volume. It was determined using the equation by Mohesenin, 1986.

$$
\varepsilon=\left(1-\frac{\rho_{b g}}{\rho_{t g}}\right)
$$

\section{Angle of repose}

The angle of repose $(\theta)$ was measured using an apparatus, which consisted of a box with a transparent face and a mirror attached on the opposite side. A scale is fixed to the transparent face to take the readings. The box has a circular plate inside it with a diameter of $80 \mathrm{~mm}$ and it has a conical opening at the bottom to allow smooth flow of grain. Initially, the box was filled with green gram and then the bottom lid was removed, causing the grains to slowly flow out of the box, resulting in the formation of a heap of green grams over the circular plate. The pile's height was measured 
through the mirror and a measuring scale placed inside the box using the formula (Singh et al., 2010, Mohesenin, 1986).

$$
\theta=\tan ^{-1}\left(\frac{2 h}{D}\right)
$$

\section{Static coefficient of friction}

The static coefficient of friction of green gram was measured against four different surfaces (mild steel, stainless steel, ply wood and galvanised iron sheet). The apparatus used for the determination of the coefficient of static friction $(\mu)$ consist of a plywood box $(165 \times 80 \times 75 \mathrm{~mm})$ kept on a flat table. The table has a frictionless pulley arrangement through which weights can be attached to the plywood box using a loading pan. Weights are added to the loading pan until the empty box began to slide over the study surface. The same box filled with grain was also allowed to slide and the corresponding weight was recorded. The experiment was conducted three times at each moisture content and the average value was recorded (Mohesenin, 1986).

Co-efficient of friction $\left(\mu_{s}\right)=\frac{\text { Lateral force } F}{\text { Normal force } N}=\frac{W_{2}-W_{1}}{W_{g}}$

\section{Co-efficient of internal friction}

For determining the co-efficiency of internal friction, the setup consisted of a flat table with a frictionless pulley arrangement and two rectangular plywood boxes with free surfaces. The dimensions of the two boxes are $285 \times 120 \times 75 \mathrm{~mm}$ and $165 \times 80 \times 75 \mathrm{~mm}$ each. While reading, the larger box is placed on the table and is filled with grain and levelled. The smaller box (empty) is kept over the grain and load is applied using the loading pan until it slides using the rope and pulley arrangement. The same experiment is further conducted with grain filled in both the boxes and the top one is made to slide over the bottom one. The grain mass (normal force) put inside the top container is taken into consideration. The difference of weights causing the top box to slide with and without the grain is the grain's frictional force. The coefficient of internal friction was calculated using the following equation (Mohesenin, 1986).

$$
\begin{gathered}
\text { Co-efficient of } \\
\text { internal friction }\left(\mu_{\mathrm{e}}\right)
\end{gathered}=\frac{\text { Lateral force } \mathrm{F}}{\text { Normal force } N}=\frac{\mathrm{W}_{3}-\mathrm{W}_{4}}{\mathrm{~W}_{\mathrm{g} 1}}
$$

\section{Terminal velocity}

The green gram's terminal velocity was determined using an air column in which the green gram was suspended in the air stream. The setup (Fig 4) has an A.C. motor and a blower arrangement and a controller was provided to control the flow of air by regulating the incoming current. During testing, grain was dropped inside the air column and the air flow rate was gradually increased until the grains are suspended on the air. At that instant, the air velocity was measured using a van vane anemometer having the least count of $0.1 \mathrm{~m} \mathrm{~s}^{-1}$ (Mohesenin, 1986).

\section{Statistical analysis}

The impact of moisture content on various physical properties of green gram (GMD, surface area, sphericity, bulk density, true density, angle of repose, etc.) was studied through Regression analysis. The curve estimation method was followed to find the best-fit curve and equation in those cases of low $\mathrm{R}^{2}$ in Linear Regression. Logarithmic, inverse, quadratic, cubic, power and $\mathrm{S}$ Regression models were studied and the best two curves were considered. Also, the effect of both material surface and moisture content on the friction coefficient of green gram was studied using Regression. The best-fit Regression models (with a high coefficient of determination, $\mathrm{R}^{2}$ and low standard error of estimation, $\mathrm{S}_{\mathrm{e}}$ ) were considered.

\section{RESULTS AND DISCUSSION}

\section{Geometric mean diameter}

The mean geometric dimensions $(\mathrm{L}, \mathrm{B}, \mathrm{T})$ of the 50 grains measured at different $\mathrm{MC}$ ( 10.58 to $45.45 \%$ d.b.), along with the standard errors, are shown in Table 1. The values indicate a rise of $12.30,8.45$ and $9.50 \%$ in the dimensions ( $L$, $B$ and $T$ ) with an increase in $M C$, respectively. The coefficients and Regression model values (Eqs. 9 to 37 ) are shown in Table 2. The GMD $\left(D_{g m}\right)$ of green gram was computed and the variation in GMD over the change in moisture content was studied using Regression analysis. The trend (Fig 1) shows the mean diameter of green gram increased (3.75 to $4.12 \mathrm{~mm}$ ) with an increase in moisture content (10.58 to $45.45 \%$, d.b.) and the Regression equations 9 and 10represent the best fit curves for the data.

$D_{g m}=4.245-\frac{5.193}{M}, \quad$ (Inverse, $\left.R^{2}=0.996\right)$

$\operatorname{Ln}\left(D_{g m}\right)=1.448-\frac{1.321}{M},\left(S-c u r v e, R^{2}=0.995\right)$

There is a $9.87 \%$ increase in the value of GMD with an increase in moisture content. This was due to increase in the overall dimension of the grain with additional gain of moisture. The high $\mathrm{R}^{2}$ value and low standard errors $(0.01$ and 0.003 ) imply the goodness of fit among the data and the variation is statistically significant $(p<0.05)$ for the range of moisture studied. Several researchers like Alibas and Koksal, 2015 (soybean) and Nimkar and Chattopadhyay. 2001, Pandiselvam et al., 2017 and Unal et al., 2008 (green gram) observed similar trends in their work.

\section{Sphericity}

The sphericity of green gram was calculated and shown in Fig 1. Equation 11 and 12 shows the relationship between MC and sphericity of grain. The data initially increased from 0.833 to 0.844 and then reduced to 0.819 . Data fitted well with cubic and quadratic curves $\left(S_{e}=0.003\right.$ and 0.002). The variation was non-significant $(p=0.208)$ for cubic function. Very less variation was observed in the sphericity of the grain within the MC studied. 
$\Phi_{g}=0.810+0.003 \mathrm{M}-6.44 \times 10^{-5}+1.47 \times 10^{-7} \mathrm{M}^{3}$,

(Cubic, $R^{2}=0.892, p>0.05$ )

$\Phi_{g}=0.812+0.003 \mathrm{M}-5.19 \times 10^{-5} \mathrm{M}^{2}$,

(Quadratic, $\mathrm{R}^{2}=0.945, \mathrm{p}<0.05$

The results of this study are in agreement with studies by Nimkar and Chattopadhyay. 2001 and Unal et al., 2008 who observed similar results for green grams through their work. Zewdu and Solomon. 2007 detected low sphericity values at higher MC for Tef seed in his study.

\section{Surface area}

The surface area of green gram changed from 44.13 to 53.45 $\mathrm{mm}^{2}$ (Fig 2), with an increase in moisture content (10.58 to $45.45 \%)$. The relation between them is established using Regression analysis (Eqs. 13 and 14).

$S_{g}=56.56-\frac{131.058}{M}, \quad\left(\right.$ Inverse,$\left.R^{2}=0.997\right)$

$S_{g}=36.57+0.865 M-0.011 M^{2}, \quad$ (Quadratic, $\left.R^{2}=0.969\right)$

Table 1: Means and standard errors of geometric dimensions of grain at different MC.

\begin{tabular}{lccr}
\hline Moisture content, \% (d.b.) & Major axis, $(\mathrm{L}), \mathrm{mm}$ & Medium axis $(\mathrm{T}), \mathrm{mm}$ & Minor axis $(\mathrm{B}), \mathrm{mm}$ \\
\hline 10.58 & $4.51 \pm 0.05$ & $3.48 \pm 0.03$ & $3.36 \pm 0.03$ \\
18.26 & $4.71 \pm 0.07$ & $3.71 \pm 0.04$ & $3.58 \pm 0.03$ \\
26.89 & $4.84 \pm 0.08$ & $3.77 \pm 0.05$ & $3.65 \pm 0.06$ \\
36.24 & $4.95 \pm 0.09$ & $3.82 \pm 0.04$ & $3.68 \pm 0.04$ \\
45.45 & $5.06 \pm 0.1$ & $3.81 \pm 0.03$ & $3.65 \pm 0.03$ \\
\hline
\end{tabular}

Table 2: Parameters of Regression models obtained through Curve fit method.

\begin{tabular}{|c|c|c|c|c|c|c|c|c|}
\hline \multirow{2}{*}{ Eqs. No. } & \multicolumn{4}{|c|}{ Model Summary } & \multicolumn{4}{|c|}{ Parameter Estimates } \\
\hline & $\mathrm{R}^{2}$ & Adjusted $\mathrm{R}^{2}$ & Std. Error, $\mathrm{S}_{\mathrm{e}}$ & Sig.(p-value) & Constant & b1 & b2 & b3 \\
\hline 9 & 0.997 & 0.996 & 0.010 & 0.00 & 4.245 & -5.193 & & \\
\hline 10 & 0.996 & 0.995 & 0.003 & 0.00 & 1.448 & -1.321 & & \\
\hline 11 & 0.973 & 0.892 & 0.003 & 0.208 & 0.810 & 0.003 & $-6.44^{*} 10^{-5}$ & $1.48^{*} 10^{-7}$ \\
\hline 12 & 0.973 & 0.945 & 0.002 & 0.027 & 0.812 & 0.003 & $-5.19^{*} 10^{-5}$ & \\
\hline 13 & 0.998 & 0.997 & 0.197 & 0.00 & 56.56 & -131.06 & & \\
\hline 14 & 0.984 & 0.969 & 0.016 & 0.016 & 36.57 & 0.865 & -0.011 & \\
\hline 15 & 0.990 & 0.986 & 0.411 & 0.00 & 30.299 & 6.075 & & \\
\hline 16 & 0.987 & 0.982 & 0.470 & 0.001 & 55.36 & -119.9 & & \\
\hline 17 & 0.977 & 0.969 & 0.013 & 0.002 & 0.622 & 2.467 & & \\
\hline 18 & 0.978 & 0.97 & 0.016 & 0.001 & -0.459 & 3.214 & & \\
\hline 19 & 0.999 & 0.998 & 0.002 & 0.00 & 1.214 & 1.219 & & \\
\hline 20 & 0.999 & 0.998 & 0.001 & 0.00 & 0.196 & 0947 & & \\
\hline 21 & 0.967 & 0.956 & 0.847 & 0.003 & 48.85 & -135.48 & & \\
\hline 22 & 0.965 & 0.954 & 0.021 & 0.003 & 3.903 & -3.348 & & \\
\hline 23 & 0.997 & 0.996 & 0.049 & 0.00 & 8.627 & 0.054 & & \\
\hline 24 & 0.997 & 0.994 & 0.057 & 0.003 & 8.690 & 0.048 & $9.98^{*} 10^{-5}$ & \\
\hline 25 & 0.980 & 0.978 & 0.868 & 0.00 & 51.56 & -214.94 & & \\
\hline 26 & 0.973 & 0.971 & 0.027 & 0.00 & 3.979 & -5.642 & & \\
\hline 27 & 0.994 & 0.992 & 0.004 & 0.00 & 0.744 & 0.003 & & \\
\hline 28 & 0.995 & 0.989 & 0.005 & 0.005 & 0.749 & 0.003 & $7.33^{*} 10^{-6}$ & \\
\hline 29 & 0.864 & 0.859 & 0.00 & 0.00 & 0.252 & 0.008 & -0.013 & \\
\hline 30 & 0.968 & 0.966 & 0.019 & 0.00 & 0.270 & 0.008 & & \\
\hline 31 & 0.968 & 0.963 & 0.020 & 0.00 & 0.271 & 0.008 & $1.393^{*} 10^{-6}$ & \\
\hline 32 & 0.945 & 0.941 & 0.022 & 0.00 & 0.212 & 0.007 & & \\
\hline 33 & 0.961 & 0.958 & 0.045 & 0.00 & 0.245 & 0.017 & & \\
\hline 34 & 0.946 & 0.942 & 0.025 & 0.00 & -0.180 & 0.191 & & \\
\hline 35 & 0.956 & 0.952 & 0.06 & 0.00 & -0.407 & -9.912 & & \\
\hline 36 & 0.954 & 0.951 & 0.027 & 0.00 & 0.176 & 0.009 & & \\
\hline 37 & 0.959 & 0.956 & 0.062 & 0.00 & 0.073 & 0.543 & & \\
\hline
\end{tabular}

The independent variable is MC. 
Both the curves fitted well for the surface area values with low $S_{e}$ and a high coefficient of determination $\left(R^{2}\right)$ and the effect was statistically significant $(p<0.05)$. It indicates that with an increase in moisture content, the grain dimensions increased significantly, resulting in a higher surface area. Similar results have been reported by Sacilik et al., 2003 (Hempseed), Sharon et al., 2015 (Black gram), Singh et al., 2010 (Barnyard millet) through their works.

\section{Mass of $\mathbf{1 0 0 0}$ grains}

With an increase in moisture content from 10.58 to $45.45 \%$ (d.b.), the mass of 1000 grains varied from $44.13 \mathrm{~g}$ to 53.45 g (Fig 2). The equations (15 and 16) displaying the relationship between grain mass and $M C$ are given below. $\mathrm{W}_{\mathrm{gt}}=30.299+6.075 \times \operatorname{Ln}(\mathrm{M}), \quad\left(\right.$ Logarithmic, $\left.\mathrm{R}^{2}=0.986\right)$

$\mathrm{W}_{\mathrm{gt}}=55.36-\frac{119.92}{\mathrm{M}} \quad\left(\right.$ Inverse, $\left.\mathrm{R}^{2}=0.982\right)$

Within MC's range, the grain mass increased by $20.39 \%$ and the variation in mass was statistically significant $(p<$ $0.05)$. The increase in 1000 grain weight was due to absorption of moisture by the molecules of the grain. The low $S_{\mathrm{e}}$ values predict the closeness among the data. Many researchers have reported a surge in the mass of 1000 grains with a rise in MC (Nimkar et al., 2005, Pandiselvam et al., 2017, Singh et al., 2010 and Sharon et al., 2015).

\section{Bulk density}

The bulk density of green gram reduced significantly $(p<$ 0.05 ) from $860 \mathrm{~kg} \mathrm{~m}^{-3}$ to $670 \mathrm{~kg} \mathrm{~m}^{-3}$ (Fig 3) with an increase in moisture content from 10.58 to $45.45 \%$. The bulk density and MC display the following relationship (Eqs. 17 and 18). The respective standard errors are 0.013 and 0.016 , which reflect close fit among the values.

$$
\begin{aligned}
& \rho_{b g}=0.622+\frac{2.467}{M}, \quad\left(\text { Inverse, } R^{2}=0.969\right) \\
& \operatorname{Ln}\left(\rho_{b g}\right)=-0.459+\frac{3.214}{M}, \quad\left(S-c u r v e, R^{2}=0.970\right)
\end{aligned}
$$

There was a reduction in bulk density by $22.09 \%$ with $M C$ and it may be due to an increase in its size and dimensions, causing more inter-granular space between the bulk. The corresponding increase in mass was less pronounced than the grains' volumetric expansion, resulting in lower bulk density. Balasubramanian and Viswanathan. 2010 (Minor millets), Nimkar and Chattopadhyay. 2001 (Green gram), Sharon et al., 2015 (Black gram), Shelke et al., 2019 (Black gram) and Unal et al., 2008 (Mung bean) have observed a decrease in bulk density values with rising in $\mathrm{MC}$ in their respective works.

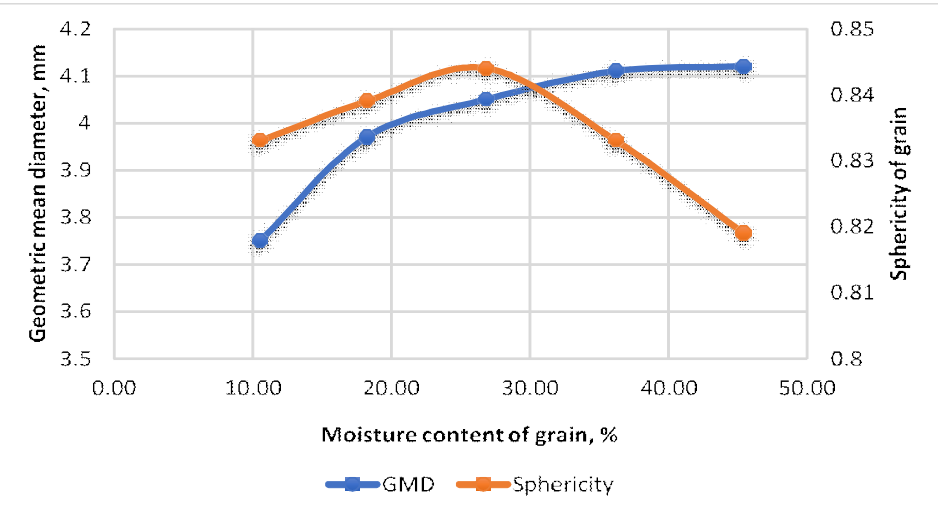

Fig 1: Effect of moisture content on geometric mean diameter (GMD) and Sphericity of grain.

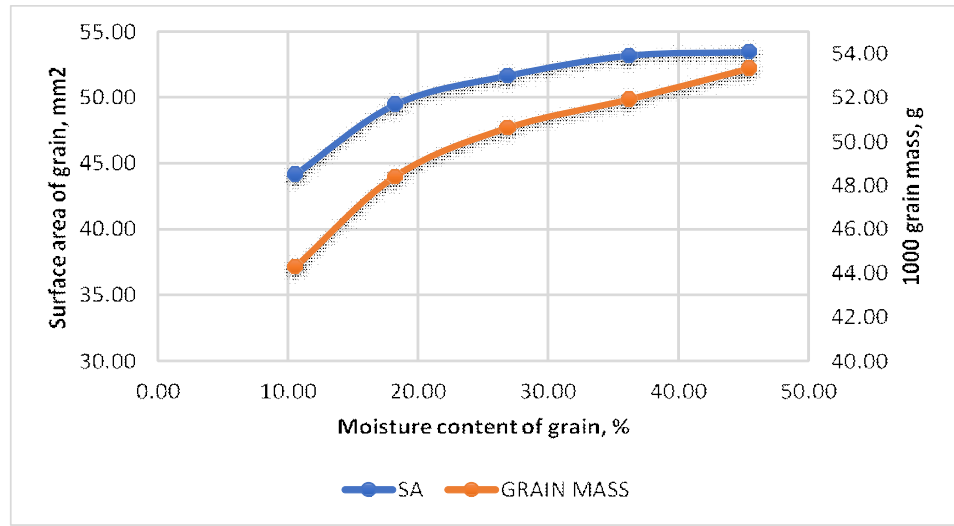

Fig 2: Effect of moisture content on surface area (SA) and 1000 grain mass. 


\section{True density (Toluene displacement method)}

True density of green gram varied from $1330 \mathrm{~kg} \mathrm{~m}^{-3}$ to 1240 $\mathrm{kg} \mathrm{m}^{-3}$ (Fig 3) with rise in moisture content from 10.58 to $45.45 \%$. The variation in true density was statistically significant $(p<0.05)$ with low $S_{e}$ values and the relation is represented by Regression equations below.

$\rho_{\mathrm{tg}}=1.214+\frac{1.219}{\mathrm{M}}, \quad\left(\right.$ Inverse, $\left.\mathrm{R}^{2}=0.998\right)$

$\operatorname{Ln}\left(\rho_{\mathrm{tg}}\right)=0.196+\frac{0.947}{M},\left(\mathrm{~S}\right.$-curve, $\left.\mathrm{R}^{2}=0.998\right)$

Relatively higher true grain volume against its rising weight is attributed to a decline in the grain's true density. The results were in accordance with several other researchers, including Nimkar and Chattopadhyay. 2001 (green gram), Nimakar et al., 2005 (Moth gram) and Sharon et al. 2015 (black gram).

\section{Porosity}

The porosity of grains is computed from the data of bulk and true densities. It was observed, with an increase in moisture content from 10.58 to $45.45 \%$, the porosity increased from 35.75 to $46.38 \%$ (Fig 4). Regression equations 21 and 22 signify the relation between porosity and $\mathrm{MC}$ of grains.

$$
\begin{aligned}
& \varepsilon=48.847-\frac{135.481}{M}, \quad\left(\text { Inverse }, R^{2}=0.956\right) \\
& \operatorname{Ln}(\varepsilon)=3.903-\frac{3.348}{M}, \quad\left(\text { S-curve }, R^{2}=0.954\right)
\end{aligned}
$$

The increase in porosity is well defined from the bulk and true density values, which declined with rising $\mathrm{MC}$. The low $p$-values and low $S_{e}$ values portray the statistical significance of MC's variation and a high correlation among the values is also observed. Nimkar and Chattopadhyay. 2001 (Green gram), Pandiselvam et al., 2017 (Green gram), Sharon et al., 2015 (Black gram) and Unal et al., 2008 (Mung bean) also reported this incline in porosity in their studies.

\section{Terminal velocity}

The terminal velocity of green gram varied significantly $(p<$ 0.05 ) from 9.20 to $11.10 \mathrm{~m} \mathrm{~s}^{-1}$ with an increase in moisture content from 10.58 to $45.45 \%$. The linear and quadratic regression equations $(23,24)$ represent a high coefficient of determination with the goodness of fit with 0.049 and 0.057 $\mathrm{S}_{\mathrm{e}}$ values, respectively.

$\mathrm{V}_{\mathrm{g}}=8.627+0.054 \mathrm{M}, \quad\left(\right.$ Linear, $\left.\mathrm{R}^{2}=0.996\right)$

$V_{g}^{g}=8.690+0.048 \mathrm{M}+9.98 \times 10^{-5} \mathrm{M}^{2}$, (Quadratic, $\left.R^{2}=0.994\right)$

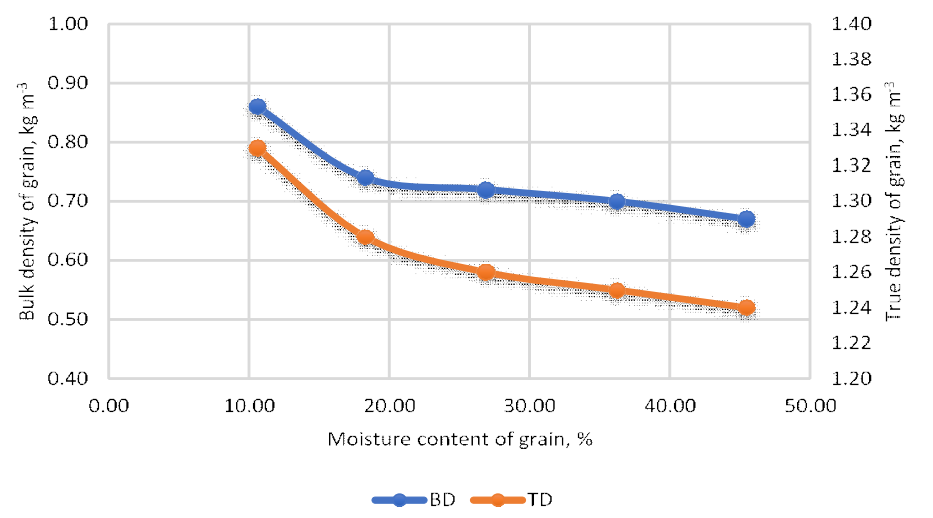

Fig 3: Effect of moisture content on bulk density (BD), true density (TD) of grain.

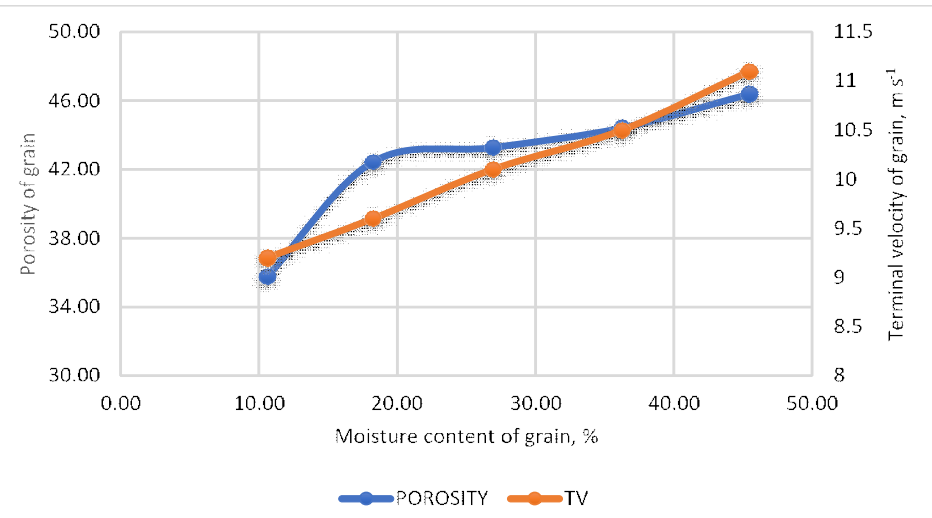

Fig 4: Effect of moisture content on porosity and terminal velocity (TV) of grain. 
The mean values of terminal velocity at different moisture levels are shown in Fig 4. The increase in terminal velocity value is due to a rise in grain mass due to moisture absorption. Nimkar and Chattopadhyay. 2001 (green gram), Nimakar et al., 2005 (Moth gram), Singh et al., 2010 (Barnyard millet and kernel) and Unal et al., 2008 (mung bean) obtained similar results during their studies on grains.

\section{Dynamic angle of repose}

The experimental values (Fig 5) confirmed that with a rise in $\mathrm{MC}$, the angle of repose increased significantly from 30.95 to $46.57^{\circ}(50.46 \%$ increase). It may be due to higher internal friction at elevated $\mathrm{MC}$ resulting from more contact surface area of the grains.

$$
\begin{array}{ll}
\theta=51.56-\frac{214.941}{M}, & \left(\text { Inverse, } R^{2}=0.978\right) \\
\operatorname{Ln}(\theta)=3.979-\frac{5.642}{M}, & \left(\text { S-curve, } R^{2}=0.971\right)
\end{array}
$$

The regression equations (25 and 26) with higher $\mathrm{R}^{2}$ values, low $p$ and $S_{e}$ values indicate good dependency and statistical significance among the data. Various other researchers reported similar outcomes from their study (Baryeh. 2002, Pandiselvam et al., 2017, Singh et al., 2010 and Unal et al., 2008).

\section{Coefficient of internal friction}

There was an increase in the mean value of coefficient internal friction from 0.78 to 0.90 (Fig 5) with increase in $M C$ of green gram. The variation in the values were represented using the equations (27 and 28 ) obtained through Regression analysis. Data shows good dependency (high $\mathrm{R}^{2}$ and low $\mathrm{S}_{\mathrm{e}}$ ) and the values are statistically significant.

$\mu_{e}=0.744+0.003 \mathrm{M}, \quad\left(\right.$ Linear, $\left.R^{2}=0.992\right)$

$\mu_{\mathrm{e}}=0.749+0.003 \mathrm{M}+7.328 \times 10^{-6} \mathrm{M}^{2}, \quad$ (Quadratic, $\left.R^{2}=0.989\right)$

The increased coefficient of internal friction at higher MC may be due to increased cohesion among the grains. Balasubramanian and Viswanathan. 2010 and Singh et al., 2010 observed similar trends for minor millets and barnyard millets, respectively.

\section{Coefficient of static friction}

The effect of different surfaces and MC (10.58 to $45.45 \%$ d.b.) on the static coefficient of friction of grain was studied using Regression and it showed a linear relationship $\left(0.859 \% R^{2}\right.$ value) and the equation (29) is presented below. The combined effects of both surface and MC were statistically significant $(p<0.05)$. The mean values of the coefficient of static friction are presented in Table 3.

$\mu_{s}=0.252+0.008 \mathrm{M}-0.013 \mathrm{~S},\left(\right.$ Linear, $\left.\mathrm{R}^{2}=0.859\right)$

Further, the impact of moisture on the friction coefficient on different surfaces was studied and the Regression equations (30 to 37) are presented below. The coefficient data of green gram shows, there is a change from 0.35 to $0.64(82.86 \%)$ for mild steel (Fig 6), 0.29 to $0.54(86.20 \%)$ for stainless steel (Fig. 6), 0.26 to 0.56 (115.38\%) for plywood (Fig 6) and from 0.26 to 0.60 (130.77\%) for galvanised iron

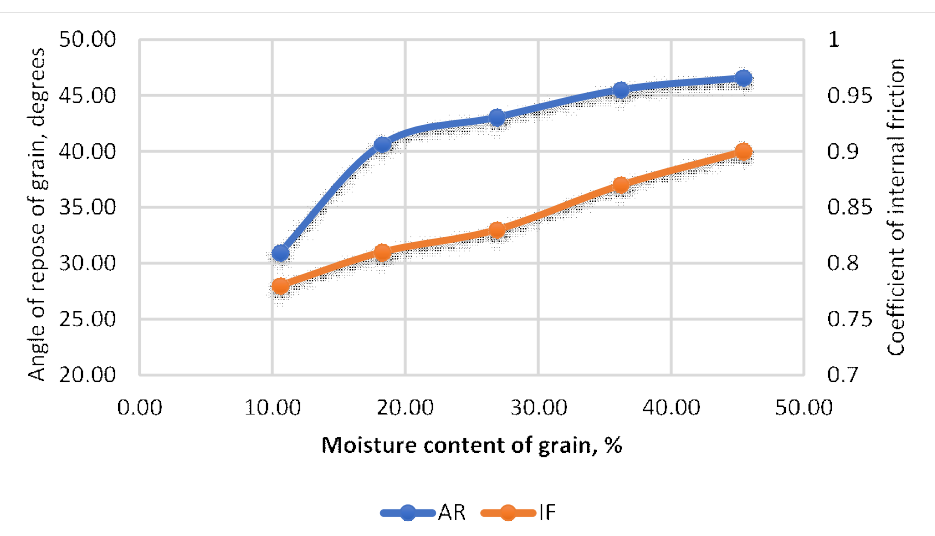

Fig 5: Effect of moisture content on angle of repose (AR) and coefficient of internal friction (IF) of grain.

Table 3: Coefficient of static friction for green gram.

\begin{tabular}{lccrr}
\hline \multirow{2}{*}{ Moisture content, \% (d.b.) } & \multicolumn{4}{c}{ Coefficient of friction, $\mu$} \\
\cline { 2 - 5 } & Mild steel & Stainless steel & Plywood & Galvanised iron \\
\hline 10.58 & $0.35(0.02)$ & $0.29(0.01)$ & $0.26(0.02)$ & $0.26(0.02)$ \\
18.26 & $0.42(0.02)$ & $0.35(0.01)$ & $0.40(0.03)$ & $0.36(0.02)$ \\
26.89 & $0.49(0.01)$ & $0.37(0.02)$ & $0.45(0.01)$ & $0.48(0.01)$ \\
36.24 & $0.54(0.02)$ & $0.44(0.02)$ & $0.56(0.02)$ & $0.50(0.04)$ \\
45.45 & $0.64(0.02)$ & $0.54(0.02)$ & & $0.60(0.03)$ \\
\hline
\end{tabular}

Numbers in parentheses are S.D.s. 


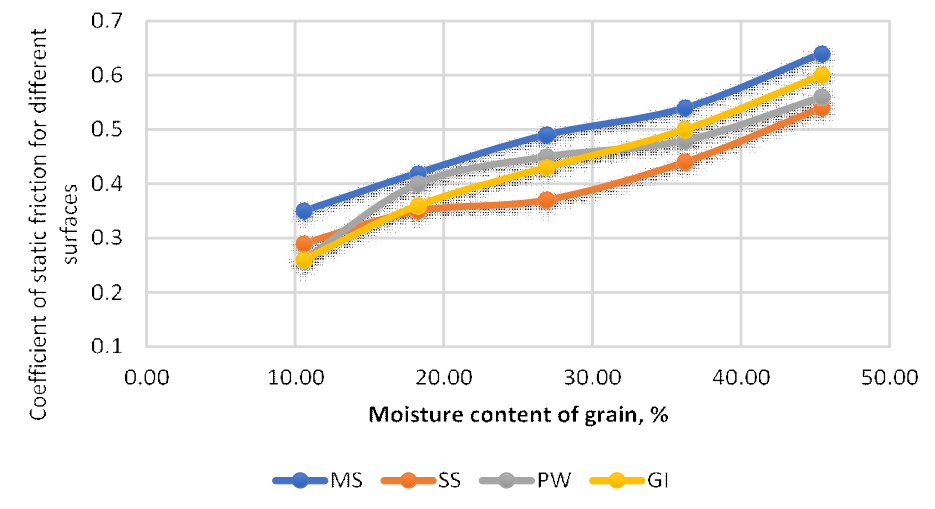

Fig 6: Effect of moisture content on coefficient of static friction of grain on different surfaces.

surface (Fig 6). The MS surface had the highest coefficient of static friction values at $45.45 \% \mathrm{MC}$, followed by $\mathrm{GI}$, plywood and stainless steel. The highest percentage of increase $(130.77 \%)$ in the coefficient of friction is observed for the GI surface and the least increase is detected for MS $(82.86 \%)$ surface within the range of $\mathrm{MC}$ studied. It might be because the mild steel surface offered the highest resistance among all the surfaces to the grain movement, while stainless steel had the least resistance due to its roughness. The static coefficient of friction for green gram increased for all the surfaces with an increase in MC due to increased adhesive force between grains and the surface. Similar results were obtained by Nimkar and Chattopadhyay. 2001, Pandiselvam et al., 2017 and Singh et al., 2010 during their research work. The relationship between moisture and coefficient of friction of grain at different surfaces are presented below.

\section{Mild Steel (MS)}

$\mu_{\mathrm{ms}}=0.270+0.008 \mathrm{M}, \quad\left(\right.$ Linear, $\left.\mathrm{R}^{2}=0.966\right)$

$\mu_{\mathrm{ms}}=0.271+0.008 \mathrm{M}+1.39 \times 10^{-6} \mathrm{M}^{2}$, (Quadratic, $\mathrm{R}^{2}=0.963$ )

\section{Stainless Steel (SS)}

$\mu_{\mathrm{ss}}=0.212+0.007 \mathrm{M}, \quad\left(\right.$ Linear, $\left.\mathrm{R}^{2}=0.941\right)$

$\operatorname{Ln}\left(\mu_{\mathrm{ss}}\right)=\operatorname{Ln}(0.245)+0.017 \mathrm{M}, \quad\left(\right.$ Exponential, $\left.\mathrm{R}^{2}=0.958\right)$

\section{Ply wood (PW)}

$\mu_{p w}=-0.180+0.191 \times \operatorname{Ln}(M),\left(\right.$ Logarithmic, $\left.R^{2}=0.942\right)$

$\operatorname{Ln}\left(\mu_{p w}\right)=-0.407-\frac{9.912}{M},\left(S-c u r v e, R^{2}=0.952\right)$

\section{Galvanised Iron (GI)}

$\mu_{\mathrm{gi}}=0.176+0.009 \mathrm{M}, \quad\left(\right.$ Linear, $\left.\mathrm{R}^{2}=0.951\right)$

$\operatorname{Ln}\left(\mu_{\mathrm{gi}}\right)=\operatorname{Ln}(0.073)+0.543 \times \operatorname{Ln}(\mathrm{M}), \quad\left(\right.$ Power, $\left.R^{2}=0.956\right)$

The regression equations of green gram for all the four surfaces reflect a high coefficient of determination $\left(R^{2}\right)$ with low $S_{e}$ values. The Regression models display the goodness of fit among the data. The $p$-values $(p<0.05)$ also imply the statistical significance of the variation with moisture increase.

\section{CONCLUSION}

The result highlights the significant effect of $M C$ on various properties of Green gram. The moisture dependent properties of grain play a crucial role for deciding optimum design parameters of any agricultural equipment for handling the grain (seed hopper, graders, sieve size) or storing them (silos, bins etc.). Due to some time constraints additional properties like grains' rupture strength and impact of loading rate and moisture on it could not be studied. Grain breakage becomes an important factor while using mechanical planters and seed drills thereby reducing germination rate. More research on factors affecting grain damage and role of $\mathrm{MC}$ needs to be conducted to minimise the loss of grains and maximise productivity.

\section{ACKNOWLEDGEMENT}

The author is grateful to OUAT, Bhubaneswar for providing necessary laboratory and research facilities during the process. The authors are thankful to RKVY, Government of India, for providing the research fund during his $\mathrm{PhD}$ degree program. The corresponding author expresses deep gratitude to the Science and Technology Department, Govt. of Odisha for providing fellowship and research assistance (BPRF) during his PhD program.

\section{REFERENCES}

Alibas, I. and Koksal, N. (2015). The effect of moisture content on physical, mechanical and rheological properties of soybean (Glycine max cv. ATAEM-II) seed. Legume Research. 38(3): 324-333.

Anonymous. (2018). Pulses Revolution from Food to Nutritional Security. Crops Division, Government of India. Ministry of Agriculture and Farmers Welfare, Department of Agriculture, Cooperation and Farmers Welfare, New Delhi, India, p.15-16.

Balasubramanian, S. and Viswanathan, R. (2010). Influence of moisture content on physical properties of minor millets. Journal of Food Science and Technology. 47(3): 279-284.

Baryeh, E.A. (2002). Physical properties of millet. Journal of Food Engineering. 51(1): 39-46. 
Dahiya, P.K., Linnemann, A.R., Van Boekel, M.A.J.S., Khetarpaul, N., Grewal, R.B. and Nout, M.J.R. (2015). Mung bean: Technological and nutritional potential. Critical Reviews in Food Science and Nutrition. 55(5): 670-688.

Dursun, E. and Dursun, I. (2005). Some physical properties of caper seed. Biosystems Engineering. 92(2): 237-245.

IS 4333 (Part 4) (2002). Determination of the mass of 1000 grains, Method for Analysis for Foodgrains, Bureau of Indian Standards, New Delhi, India. p-1-2.

Mangaraj, S., Agrawal, S., Kulkarni, S.D. and Kapur, T. (2005). Studies on physical properties and effect of pre-milling treatments on cooking quality of pulses. J. Food Sci. Technol. 42: 258-262.

Mohsenin, N.N. (1986). Physical Properties of Plant and Animal Materials, $2^{\text {nd }} \mathrm{Ed}$. Gordon and Breach Science Publishers, New York. 1986, p-108.

Nimkar, P.M. and Chattopadhyay, P.K. (2001). PH-Postharvest Technology: Some physical properties of green gram. Journal of Agricultural Engineering Research. 80(2): 183189.

Nimkar, P.M., Mandwe, D.S. and Dudhe, R.M. (2005). Physical properties of moth gram. Biosystems Engineering. 91(2): 183-189.

Niveditha, V.R., Sridhar, K.R. and Balasubramanian, D. (2013). Physical and mechanical properties of seeds and kernels of Canavalia of coastal sand dunes. Int. Food Res. J. 20(4): 1547-1554.

Pandiselvam, R., Thirupathi, V., Kothakota, A. and Kamalapreetha, B. (2017). Important engineering properties of green gram (Vigna radiata). Agricultural Engineering Today. 41(4): 3036.

Pandiselvam, R., Thirupathi, V., Mohan, S. (2015). Engineering properties of rice. Poljoprivredna Tehnika. 40(3): 69-78.
Pawase, P A., Shingote, A. and Chavan, U. D. (2019). Studies on evaluation and determination of physical and functional properties of millets. (Ragi and Pearl millet). Asian Journal of Dairy and Food Research. 38(3): 203-212.

Sacilik, K., Öztürk, R. and Keskin, R. (2003). Some physical properties of hemp seed. Biosystems Engineering. 86(2): 191-198.

Sahay, K.M. and Singh. K.K. (1986). Unit Operations of Agricultural Processing. Vikas Publishing House Pvt. Ltd., p-6.

Sharon, M.E.M., Abirami, C.K., Alagusundaram, K. and RPS, J.A. (2015). Moisture dependent physical properties of black gram. Agricultural Engineering International: CIGR Journal. 17(1). 181-187.

Shelke, G.N., Pandiarajan, T. and Modi, R.U. (2019). Effect of moisture content on engineering properties of black gram (Vigna mungo). Research Journal of Agricultural Sciences. 10(1): 180-184.

Singh, A. K., Singh, S. S., Prakash, V., Kumar, S. and Dwivedi, S. K. (2015). Pulses Production in India: Present Status, Bottleneck and Way Forward, Journal of Agri Search. 2(2): 75-83.

Singh, K.P., Mishra, H.N. and Saha, S. (2010). Moisture-dependent properties of barnyard millet grain and kernel. Journal of Food Engineering, 96. 598-606.

Unal, H., Isık, E., Izli, N. and Tekin, Y. (2008). Geometric and mechanical properties of mung bean (Vigna radiata L.) grain: Effect of moisture. International Journal of Food Properties. 11(3): 585-599.

Varsha, R. and Grewal, R.B. (2014). Physical and functional properties of six varieties of lentil (Lens culinaris Medik.). Asian Journal of Dairy and Food Research. 33(2): 126130.

Zewdu, A.D. and Solomon, WK. (2007). Moisture-dependent physical properties of tef seed. Biosystems Engineering, 96(1): 57-63. 